\title{
The Study of Processes Affecting Groundwater Hydrochemistry by Multivariate Statistical Analysis (Case Study: Coastal Aquifer of Ghaemshahr, NE-Iran)
}

\author{
Homayoun Moghimi \\ Geology Department, Payam-e Noor University, PO Box 19395-4697, Tehran, Iran \\ Email:homayounmoghimi@pnu.ac.ir
}

How to cite this paper: Moghimi, H. (2017) The Study of Processes Affecting Groundwater Hydrochemistry by Multivariate Statistical Analysis (Case Study: Coastal Aquifer of Ghaemshahr, NE-Iran). Open Journal of Geology, 7, 830-846.

https://doi.org/10.4236/ojg.2017.76057

Received: February 24, 2017

Accepted: June 12, 2017

Published: June 15, 2017

Copyright $\odot 2017$ by author and Scientific Research Publishing Inc. This work is licensed under the Creative Commons Attribution International License (CC BY 4.0).

http://creativecommons.org/licenses/by/4.0/

\begin{abstract}
To assess the quality of groundwater resources, samples were collected from 22 points for mean annual water years of 2003 and 2015 (mean minimum and maximum water table), and 19 parameters were examined and calculated. One of the objectives of this study was to evaluate the groundwater quality of the Ghaemshahr plain which includes the study of spatial and temporal changes of groundwater quality in different sectors and factors affecting it. In this study, combining statistical methods such as Pearson correlation coefficient, factor analysis, principal component analysis, and combined diagrams with hydrochemical methods are used to assess the chemical quality of groundwater. Samples were categorized by using cluster method and then the same samples were identified. Accordingly, samples were classified in four categories which represent the quality of groundwater in different districts. Factor analysis was used to identify the factors affecting the geochemical processes of the aquifer. Statistical methods showed that they can be used to complete the conventional methods in hydro-geochemistry as well as very precise results can be achieved. Based on the obtained results, saturation index of Ghaemshahr groundwater was super-saturated; and groundwater quality control of Ghaemshahr plain is hold by processes such as dissolution of halide (salt water intrusion of Caspian Sea and brackish fossil aquifers), calcite and dolomite (dissolution of limestone, dolomite, and marl in height), weathering sodium-rich plagioclases (clay minerals), and ion exchange.
\end{abstract}

\section{Keywords}

Caspian Sea, Multivariate Analysis, Principal Component Analysis (PCA), Factor Analysis (FA) 


\section{Introduction}

Water is a matrix of life and it is essential for all biological ecosystems; it is the life fluid and the material for the growth of vital developments on this planet that is habitat of all living beings [1]. Determining the interactions and studying processes affecting groundwater quality in coastal aquifer are very complex. Analysis of materials, aerobic respiration, iron reduction, cation exchange, saltfresh water mixing, and so forth is the variety of the process of different biological, physical, and chemical parameters in aquifer. In recent years, multivariate statistical analysis has been widely applied to provide quantitative values and its relationship with qualitative parameters of water and to present the existing processes in groundwater aquifers. These studies are useful to: evaluate and interpret qualitative data set of groundwater [2]; provide proper vision to created processes; and identify issues related to possible sources of contamination or pollution processes, the interaction between river water and groundwater and mixing of groundwater's [3]. Ground waters' quality is controlled through many factors such as the combination of precipitation, geology and mineralogy of the ingredients' composition of aquifer, topography, climatic condition, and so on. The interaction between these factors occurs on the quality parameters in a winding path; therefore, the temporal and spatial changes would be created. Due to the synergic effects of hydrological and biogeochemical multilateral factors, it is very hard to identify the relationship between groundwater quality parameters and biogeochemical stages through graphical methods [4]. Geological and hydrogeological processes are often complex and this complexity becomes more visible with non-uniform distributions in many measurements [5]. Temporal and spatial measurements of chemical or physical processes cannot usually reveal clearly the main ruling processes. Multivariate analyses are trying to interpret or reveal the main ruling processes by data reduction and classification [6]. The results from the factor analysis in the studied area of Zoweircherry and Kherran plains (Khuzestan province, SW Iran) reflect three major factors which have about 77 percent of the total amount of the subscription. It includes the chemical processes of the dissolution of the salt, the infiltration of sodium chloride water from side of seasonal waterway; in Factor-2, the dissolution of gypsum, and in Factor-3, bicarbonate had the highest factor loading, which represent recharging from precipitation [6].

Actual hydrological data are often very high and often they do not have a normal distribution and they can sometimes be far from the reality and involve error. In order to avoid this problem, the statistical methods can be used. In this article, multivariate analysis is used such as principal component analysis; factor analysis to extract hidden processes affecting groundwater as well as on the effects of natural factors and human activities in the studied aquifer area.

In this research, hydrogeological, physico-chemical, and hydro-geochemical data were combined to use in analysis, Chemical control mechanism of groundwater and effective factors by using the factor analysis (FA) and principal component analysis (PCA) methods for physicochemical condition of groundwater's 
in the study area of Ghaemshar. The main focus in this study was to use and compare usual hydro-geochemical methods with multivariate statistical methods and combined charts. The purpose of this research was not to replace statistical methods, but it was to use and help the conventional methods.

The objectives of using multivariate methods in this study can be classified as follows:

1) Classification scheme like the quality classification of water and sampling points.

2) To form and describe data statistical population, how spatial distribution of wells and variables and responses taken place in this area.

3) How to use statistical methods and to evaluate and interpreted these methods with conventional methods.

4) The comparison of the statistical results with conventional methods of hydro-geochemistry (Piper graph and combined diagrams) in line with more correct interpretation and assessment of effective factors and the effectiveness of chemical reactions in the study area.

\section{Geographical Location, Climate, and Geology of the Study Area}

This study area is limited from the north with the Caspian Sea and from the south with the Alborz Mountain. The study area is located in geographic location of $52^{\circ} 35^{\prime} \mathrm{E}$ to $52^{\circ} 23^{\prime} \mathrm{E}$ longitude and $35^{\circ} 44^{\prime} \mathrm{N}$ to $36^{\circ} 47^{\prime} \mathrm{N}$ latitude in Mazandaran Province. The total area of the study area is approximately $3348.1 \mathrm{Km}^{2}$, of which $935.5 \mathrm{Km}^{2}$ is plain and the rest $\left(2412.6 \mathrm{Km}^{2}\right)$ is the northern slopes of the Alborz Mountains.

Watershed according to the geomorphology and condition and type of geological formations of the terms of hydrogeology is also the subject of condition of the area and thus, water table curves of groundwater level follow a certain order. Based on, unit hydrograph curves are influenced by the surface morphology, recharge zone (Southern regions) and unconfined aquifer drainage (North regions and adjacent to the beach). Since mean sea level of the Caspian Sea is minus $27 \mathrm{~m}$ lower than the open sea level, groundwater level curves' digits in the study area ranged between 60 to $-25 \mathrm{~m}$ and they declined from south to north. The general direction of groundwater flow in the area is from the south to the north and north-east. Climatic condition prevailing on Ghaemshar plain is affected by marine moisture and mountain climate.

Accordingly, mean annual rainfall in the study area was about $730 \mathrm{~mm}$ which its maximum is related to the months of November and December and its minimum is related to the months of June and July. The average annual air temperature of Ghaemshahr is $17.2^{\circ} \mathrm{C}$ which August and January are the warmest and the coldest months of the year, respectively.

Ghaemshahr-Joybar plain like other alluvial aquifer of the Caspian Sea coastline is like a bowl which gradually shaped of sea depression [7]. This plain in the southern and northern ends has low thickness and in the middle part has $200 \mathrm{~m}$ 
to $250 \mathrm{~m}$ deep which is calculated through geophysical studies [8]. Along with the retreat of the sea, fresh water's front tries to wash and push back the salt water from the mountains, but this has not been completed and across the alluvium, the saltwater limitation have remained. Over time, saline waters have formed brackish fossil aquifers during the geological periods and their covering by carried sediments. Fresh and salt water balance was disturbed due to excessive withdrawals, and it made inappropriate quality of groundwater resources, especially in output areas of the plain [9]. Geological formations have the most and major impact on water resources (quality and quantity) of GhaemshahrJoybar basin. The altitudes of this basin mostly include calcareous sediments, marl, dolomite, and sandstone (Jurassic, Cretaceous, and Eocene). The plain includes deposits of alluvial from south to north, and it is formed from finegrained sediments in the middle towards the beach. In the plain surface, the deposits include sand, soft clays, silt, and thin layer of volcanic ash which are defined as the New Caspian sediments (Quaternary). Absheron' formation has been placed below these sediments which it is formed from clay, marl, soft sand, conglomerate, and a thin layer of volcanic ash with upper Pliocene-Quaternary age. Alluvial fans and new Caspian deposits are defined as permeable and semipermeable Absheron formations in terms of hydrogeology. This classification has been conducted based on the aggregation, sorting, porosity, shape, and size (by log wells), geophysical studies, and a limited number of pumping tests.

\section{Data and Methodology}

In this research, the geological, hydrogeological, and hydro-geochemical data were used to study the properties of the aquifer and SPSS-16 software was used to analyze and interprets the data by factor analysis (FA) and principal component analysis (PCA). With the help of software, data were standardized and multivariate statistical analysis was performed. Data were collected from the average of water samples analyzed from 22 wells in both 2003 and 2015 from wells in operation and 21 elements were studied in effective and dominant processes on the unconfined coastal aquifer quality of Ghaemshahr plain. In this study, AqQa 1.5 software was applied to determine the chemical status of groundwater resources and Excel software was used to draw graphs. In this research, the study area is divided from south to north (recharge to drainage) to three parts including piedmont (recharge), central and coastal (drainage); and wells have been studied from West to East.

Water samples' analysis was used to multivariate statistical analysis which contains measurement of major cations and anions' concentration and parameters such as EC, T.D.S, pH, and hardness. America Public Health Association [1] standard was used to analyze the elements. Concentrations of sodium and potassium were calculated by Flame Photometer method; concentrations of calcium, magnesium, bicarbonate, and chloride were calculated by volumetric method; and concentration of sulfate was calculated by spectrophotometer; conductivity and total dissolved solids were measured through a conductivity meter; hardness 
values, saturation indices, color-alkaline, and alkalinity were calculated through chemical relationships. Before performing multivariate methods, data collection was tested in terms of normality. Kolmogorov-Smirnov (K-S) test was used to identify the normality of the data. The statistical description and Pearson correlation values of the data after standardization are presented in Table 1 and Table 2, respectively.

Multivariate statistical methods such as factor analysis (FA), principal component analysis (PCA) and the states of R-mode and Q-mode were used in this study. These methods effectively help to conventional methods to analyze and interpret the hydro-geochemical situation of the study area. Coefficient of KMO (Kaiser Meyer Olkin) method was used to determine and identify the suitability of data for factor analysis which its value has always fluctuated between zero and one. This factor in the study area in both years was between $0.65-0.75$, which indicates that the proportion is balanced to moderate. As a result, factor analysis according to the amount of KMO placed in the appropriate category and it can be used in this study.

It is one of the multivariate statistical methods to analyze information in the

Table 1. (a) Statistical characteristics of chemical analysis of selected sources in Ghaemshahr plain area (Ions and TDS values as $\mathrm{mg} / \mathrm{l}$ and $\mathrm{EC}$ as $\mu \mathrm{S} / \mathrm{cm}$ for 2003) (Mazandaran regional water authority, 2016), (Me; mean, Mo; mode, SD; standard deviation, S; skewness, K; kurtosis, CV; coefficient of variance). (b) Continuous table 1 for year of 2015.

(a)

\begin{tabular}{|c|c|c|c|c|c|c|c|c|c|c|c|c|c|c|c|c|c|c|c|}
\hline $\mathbf{P}$ & EC & TDS & ${ }_{\mathrm{p}} \mathrm{H}$ & $\mathrm{Ca}$ & $\mathrm{Mg}$ & $\mathrm{Na}$ & K & $\mathrm{HCO}_{3}$ & $\mathrm{Cl}$ & $\mathrm{SO}_{4}$ & TDI & SIc & SId & SIhal & SIg & Alk & CAI & CAII & TH \\
\hline Min & 792 & 522.5 & 7.5 & 74.8 & 31.6 & 22.7 & 2.2 & 250.1 & 35.01 & 73.9 & 571 & 0.41 & 6.51 & -0.20 & -16.2 & 212.2 & -1.65 & -0.4 & 572 \\
\hline Max & 3885 & 2486.4 & 8.21 & 241.5 & 111.3 & 470. & 10. & 1037 & 577.5 & 624.7 & 2560 & 1.68 & 7.98 & -0.14 & -1.9 & 818.2 & -0.06 & 0.0 & 1730. \\
\hline $\mathrm{Me}$ & 2129. & 1357 & 7.8 & 136.5 & 60.7 & 204 & 5.2 & 568.6 & 229 & 244 & 1450 & 1.2 & 7.41 & -0.16 & -6.2 & 453 & -0.43 & -0.1 & 988 \\
\hline Med & 1855 & 1212 & 7.8 & 137.8 & 50.2 & 157 & 4.2 & 539.5 & 150.8 & 158 & 1292 & 1.2 & 7.3 & -0.16 & -4.0 & 427 & -0.4 & -0.1 & 927 \\
\hline Mo & 1855 & 1212 & 7.8 & 88.5 & 42.7 & 143 & 3.9 & 381.2 & 46 & 160 & 560.7 & 1.3 & 6.3 & -0.16 & -16 & 208 & -0.4 & -0.2 & 879 \\
\hline SD & 928 & 573.7 & 0.2 & 44.1 & 23.2 & 152 & 2.1 & 218.5 & 179.5 & 159 & 596.6 & 0.37 & 0.51 & 0.02 & 3.93 & 173.3 & 0.32 & 0.10 & 327.2 \\
\hline$S$ & 0.58 & 0.61 & 0.44 & 0.89 & 1.19 & 0.70 & 0.73 & 0.57 & 0.80 & 1.21 & 0.55 & -0.5 & -0.4 & -0.16 & -1.1 & 0.52 & -2.0 & -0.8 & 1.1 \\
\hline $\mathrm{K}$ & -0.49 & -0.52 & -0.3 & 0.79 & 0.41 & -0.98 & 0.15 & -0.25 & -0.77 & 0.74 & -0.53 & -0.8 & -0.5 & -0.98 & 0.48 & -0.36 & 6.15 & -0.2 & 0.92 \\
\hline $\mathrm{CV}$ & 0.435 & 0.422 & 0.02 & 0.32 & 0.38 & 0.74 & 0.4 & 0.38 & 0.78 & 0.65 & 0.41 & 0.3 & 0.07 & -0.13 & -0.6 & 0.38 & -0.7 & 0.62 & 0.33 \\
\hline
\end{tabular}

(b)

\begin{tabular}{|c|c|c|c|c|c|c|c|c|c|c|c|c|c|c|c|c|c|c|c|}
\hline $\mathbf{P}$ & EC & TDS & ${ }_{\mathrm{p}} \mathrm{H}$ & $\mathrm{Ca}$ & $\mathrm{Mg}$ & $\mathrm{Na}$ & $\mathrm{K}$ & $\mathrm{HCO}_{3}$ & $\mathrm{Cl}$ & $\mathrm{SO}_{4}$ & TDI & SIc & SId & SIhal & SIg & Alk & CAI & CAII & TH \\
\hline Min & 868 & 554 & 7.52 & 74.8 & 29 & 22.7 & 3.43 & 255 & 31.2 & 47.5 & 686 & 0.07 & 5.74 & -0.18 & -11.5 & 193.3 & -0.45 & -0.12 & 552 \\
\hline $\operatorname{Max}$ & 7014 & 4712 & 8.3 & 355 & 142.8 & 920 & 5.73 & 1025 & 1569 & 524 & 6152 & 1.50 & 7.62 & -0.11 & -1.1 & 793.7 & 0.25 & 0.51 & 2493 \\
\hline $\mathrm{Me}$ & 1936 & 1244 & 7.85 & 145.1 & 58.9 & 155 & 4.2 & 555 & 254.7 & 128 & 1648 & 0.66 & 6.44 & -0.15 & -3.0 & 438 & -0.0 & -0.0 & 1021 \\
\hline Med & 1480 & 946.5 & 7.79 & 136.7 & 49.4 & 73 & 3.72 & 511 & 127.2 & 94.1 & 1347 & 0.6 & 6.4 & -0.16 & -2.3 & 411.8 & -0.4 & -0.1 & 955 \\
\hline Mo & 852 & 544.3 & 7.99 & 101.5 & 50.5 & 22.3 & 3.79 & 250 & 122 & 88.1 & 674 & 0.07 & 5.96 & -0.16 & -2.1 & 189.8 & -0.2 & -0.2 & 542 \\
\hline $\mathrm{SD}$ & 1354 & 861.5 & 0.25 & 62 & 25.3 & 198 & 0.74 & 192 & 336.4 & 100 & 1180 & 0.38 & 0.54 & 0.02 & 2.12 & 151.6 & 0.15 & 0.12 & 434.4 \\
\hline$S$ & 3.02 & 3.05 & 0.07 & 2.22 & 2.16 & 3.2 & 0.79 & 0.93 & 3.37 & 3.4 & 3.1 & 0.58 & 0.81 & 0.76 & -3.3 & 0.67 & -0.6 & 3.17 & 2.27 \\
\hline $\mathrm{K}$ & 11 & 11.2 & 0.52 & 6.68 & 6.27 & 12.4 & -0.4 & 0.91 & 13.1 & 14.1 & 11.9 & -0.4 & -0.1 & 0.72 & 13.0 & 0.36 & 0.82 & 12.3 & 6.81 \\
\hline $\mathrm{CV}$ & 0.7 & 0.69 & 0.03 & 0.42 & 0.43 & 1.3 & 0.17 & 0.34 & 1.32 & 0.78 & 0.71 & 0.57 & 0.08 & -0.13 & -0.7 & 0.34 & -0.7 & 0.62 & 0.42 \\
\hline
\end{tabular}


Table 2. Pearson correlation coefficient between the groundwater quality parameters of Ghaemshar plain (2003 and 2015).

\begin{tabular}{|c|c|c|c|c|c|c|c|c|c|c|c|c|c|c|c|c|c|c|}
\hline 2015 & C & CDS & ?H & $\mathrm{Ca}$ & $\mathrm{Mg}$ & $\mathrm{Na}$ & $\mathbf{K}$ & $\mathrm{HCO}_{3}$ & $\mathrm{Cl}$ & $\mathrm{SO}_{4}$ & TDI & SIc & SId & SIh & SIg & Alk & TH & 2003 \\
\hline EC & 1 & & & & & & & $0.58^{* *}$ & $0.9^{* *}$ & $0.7^{* *}$ & $0.1^{\star \star}$ & $0.43^{*}$ & & & & & & EC \\
\hline TDS & & 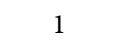 & & & & & $\underline{0.82^{* *}}$ & & $\underline{0.9^{* *}}$ & $\underline{0.8^{* *}}$ & $0.1^{* *}$ & 0.4 & $0.6^{* *}$ & $\underline{0.9 * *}$ & $\underline{-0.77^{* *}}$ & $0.5^{* *}$ & & TDS \\
\hline PH & & & 1 & & & & & & 0.1 & & 0.06 & & & & & 0.07 & & PH \\
\hline $\mathrm{Ca}$ & & & & 1 & & & $0.72^{* *}$ & & 0.31 & $0.7^{* *}$ & $0.7^{* *}$ & $0.6^{* *}$ & & $0.43^{\star}$ & & & & $\mathrm{Ca}$ \\
\hline $\mathrm{Mg}$ & & & 0.26 & $.96^{* *}$ & 1 & & $\underline{0.79 * *}$ & $0.63^{* *}$ & 0.38 & $0.68^{* *}$ & $0.72^{* *}$ & $0.41^{*}$ & & 0.41 & $-0.66^{* *}$ & & & $\mathrm{Mg}$ \\
\hline $\mathrm{Na}$ & & $00 * *$ & 10 & & & 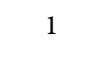 & $0.65^{* *}$ & 0.7 & $\underline{0.97^{* *} c}$ & & $+0.89^{* *}$ & 0.23 & 0.4 & $\underline{0.94^{* *}}$ & & & & $\mathrm{Na}$ \\
\hline K & & & 0.34 & & & & 1 & $0.59 * *$ & 0.014 & & $\underline{0.8^{* *}}$ & 0.34 & $0.57^{* *}$ & & & & & K \\
\hline $\mathrm{HCO}_{3}$ & & & 0.16 & & & & $0.68^{* *}$ & 1 & 0.22 & 0.08 & $0.61^{* *} c$ & $0.68^{* *}$ & & 0.41 & & $0.1^{\star *}$ & $0.63^{* *}$ & $\mathrm{HCO} 3$ \\
\hline $\mathrm{Cl}$ & $\underline{0.98^{* *}}$ & $\underline{0.97^{* *}}$ & 0.19 & $\underline{0.88^{* *}}$ & $\underline{0.9 * *}$ & $\underline{0.99^{* *}}$ & $0.74^{* *}$ & $0.63^{* *}$ & 1 & $0.67^{* *}$ & ${ }^{+0.86^{* *}}$ & 0.2 & 0.35 & $\underline{0.9^{* *}}$ & $-0.67^{* *}$ & 0.23 & 0.45 & $\mathrm{Cl}$ \\
\hline $\mathrm{SO}_{4}$ & $0.92^{* *}$ & $\underline{0.92^{* *}}$ & 0.17 & $\underline{0.9^{* *}}$ & $\underline{0.9^{* *}}$ & $\underline{0.91^{* *}}$ & $0.64^{\star \star}$ & $0.64^{\star *}$ & $0.90^{* *}$ & 1 & $0.74^{* *}$ & 0.15 & 0.41 & $0.58^{\star *}$ & $-0.99^{* *}$ & 0.082 & & $\mathrm{SO} 4$ \\
\hline TDI & $\underline{0.99^{* *}}$ & $\underline{0.98^{* *}}$ & 16 & $\underline{0.9^{* *}}$ & $\underline{0.95^{* *}}$ & $\underline{0.98^{* *}}$ & $0.74^{* *}$ & $0.68^{\star *}$ & $0.98 * * 0$ & $0.93^{* *}$ & 1 & $0.47^{\star}$ & $0.68^{* *}$ & $\underline{0.87^{* *}}$ & $-0.7^{\star *}$ & $0.6^{* *}$ & $\underline{0.79^{* *}}$ & TDI \\
\hline SIc & & & & & & & & & 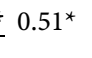 & $0.5^{\star}$ & $0.55^{\star *}$ & 1 & & & & $0.7^{* *}$ & & \\
\hline SId & $\underline{0.77^{* *}}$ & $\underline{0.76^{* *}}$ & $0.61^{\star *}$ & & $\underline{0.86^{* *}}$ & & $\underline{0.77^{* *}}$ & $\underline{0.87^{* *}}$ & & & & & 1 & $0.48^{*}$ & & $\underline{0.77 *}$ & $\underline{0.83^{* *}}$ & SId \\
\hline SIh & $\underline{0.87^{* *}}$ & $\underline{0.87^{* *}}$ & 0.22 & & $\underline{0.86^{* *}}$ & $\underline{0.86^{* *}}$ & $\underline{0.8^{* *}}$ & $\underline{0.76^{* *}}$ & & & 0.00 & $0=7 x$ & & 1 & $-0.6^{* *}$ & & & sin \\
\hline SIg & $-0.91^{* *}$ & $\underline{-0.92^{* *}}$ & -0.19 & $\underline{-0.91^{* *}}$ & $\underline{-0.92^{* *}}$ & $-0.9^{* *}$ & & & & & & & & & 1 & -0.05 & & SIg \\
\hline All- & & & 0.12 & $\underline{0.8^{* *}}$ & & $0.57^{\star *}$ & $0.72^{\star *}$ & $\underline{0.91^{* *}}$ & & 5 57** & $+0.6^{* *} 0$ & $0.64^{* *}$ & 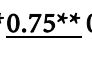 & & -0.50 & 1 & $0.66^{* *}$ & Alk \\
\hline $\mathrm{TH}$ & $\underline{0.96^{* *}}$ & $\underline{0.95^{* *}}$ & 0.22 & $\underline{0.99^{* *}}$ & $\underline{0.98^{* *}}$ & $\underline{0.9^{* *}}$ & $\underline{0.8^{* *}}$ & $\underline{0.84^{* *}}$ & $0.91^{* *} \mathrm{C}$ & $0.92^{* *}$ & $0.91^{* *} 0$ & $0.74^{\star *}$ & $0.89^{* *}$ & $0.85^{\star *}$ & $-0.91^{* *}$ & $0.79^{* *}$ & 1 & $\mathrm{TH}$ \\
\hline
\end{tabular}

${ }^{* *}$ Correlation is significant at the 0.01 level (2-tailed), ${ }^{*}$ Correlation is significant at the 0.05 level (2-tailed).

data set in factor analysis method. In fact, factor analysis is the spread of principal component analysis (PCA). In both methods (PCA, FA), it is an effort to approximate the covariance matrix, but this approximation in the factor analysis model has greater precision and delicacy. In general, the geological processes are usually complex and these complexities are clearly recognizable with non-uniform distribution in the measurements. Since the researches of natural resources such as water resources are carried out in the alluvial and hard plains' field, environmental condition is not controlled by the researcher. As a result, temporal and spatial measurements of physical and chemical processes cannot properly reveal the main ruling processes on the study area. With the help of multivariate analyses, it is attempted to interpret and to reveal the main governing processes with data reduction and their classification. This is used to determine the most effective variables when there are a large number of variables and the relationship between them is unknown. These methods are able to complete graphical limitations in interpreting hydro-geochemical trend of the study area [8] [9] [10] [11]. In this method, the variables are placed in factors as percentage of the variance is reduced from the first factor to subsequent factors, hence the variables, which are in the former factors, are the most influential. The aim of factor analysis is explanation and justification of observed correlations. This means that factors need to be interpreted as certain. To achieve this purpose, not-rotated solutions (primary factors) do not work. The reason for this is that it is difficult to identify the factors that have a large number of factor loading; and on the 
other hand, there is not an ideal and complete solution in factor analysis. Therefore, the results of factor analysis cannot be trusted without rotation.

In the case of ion exchange, [5] chloro-alkaline indexes I and II are suggested. This index represents the ion exchange between the groundwater and the host environment. Chloro-alkaline indexes can be obtained from the following equation:

$$
\begin{gathered}
(\mathrm{Cl}-(\mathrm{Na}+\mathrm{K})) / \mathrm{Cl} \\
(\mathrm{Cl}-(\mathrm{Na}+\mathrm{K})) /\left(\mathrm{SO}_{4}+\mathrm{HCO}_{3}+\mathrm{CO}_{3}+\cdots\right)
\end{gathered}
$$

Indices I and II show the changes in the chemical composition of groundwater in the movement the direction of the feeding up to be discharged. Ion exchange between $\mathrm{Na}$ and $\mathrm{K}$ are usually found in water with calcium and magnesium in the soil or rock takes place. If index is positive for the ion exchange takes place directly. But if it is negative, the opposite is taking place.

\section{Discussion and Results}

In the study area using hydro-geochemical traditional methods and multivariate statistical methods for analysis, control mechanisms of groundwater chemistry and affecting factors were used. In the analyses, the relationship of geological conditions, intrusion of marine water, brackish fossil aquifers, atmospheric waters, and chemical reactions taken place between these factors in the study area and other factors affecting the groundwater is considered. Statistical profile of chemical analysis of the study area is presented in Table 1. Minimum, maximum, mean, standard deviation, skewness values, and coefficient of variation of chemical parameters are provided in this table. Minimum values have not changed much in two years, but an abnormal increase can be seen in maximum values only in one well, which the most important reason is the influence of saline solution from fossil aquifer (given that halide and gypsum sediments does not exist in the area) and to some extent may have been caused by sea saltwater intrusion. According to geological condition and solutions penetrated into the aquifer, and as a result of taken chemical reactions, waters are created with different specifications (bicarbonate, chloride and mixing), thus the ion frequency in 2003 was as: $\mathrm{Na}+\mathrm{K}>\mathrm{Ca}>\mathrm{Mg}, \mathrm{HCO}_{3}>\mathrm{SO}_{4}>\mathrm{Cl}$; and in 2015 was as: $\mathrm{Ca}>$ $\mathrm{Na}+\mathrm{K}>\mathrm{Mg}, \mathrm{HCO}_{3}>\mathrm{Cl}>\mathrm{SO}_{4}$. This frequency can be due to the following reasons:

- Consumption of various fertilizers and their dissolution in water-soil range, and then their leakage into groundwater;

- Sea saltwater intrusion, leaking and spraying sodium and chloride ions into the aquifer;

- Indiscriminate harvesting causes the water table drawdown and facilitates the intrusion of salt water;

- Evaporation of the water table causes different salts' deposition and their re-dissolution increases the amount of salt in the aquifer.

According to the normal test and assuming test error $(\alpha) 0.05$, all the selected 
factors have a probability value (P-value) more than the test error $(\alpha)$, so there is no reason to reject the assumption of normal data (Table 2). In Table 2, the correlation values were calculated with the significant level of 0.01 and 0.05 , respectively. Significant correlated values with a 0.01 error value showed with two stars and with a 0.05 error value showed with one star. Values less than 0.5 means low or weak linear correlation, values between 0.5 to 0.75 (bold number) means significant linear correlation, and values between 0.75 and 1 (under line bold number) is defined as high linear correlation. As a result, significant values even if they have two or one star can also show good correlation. While no star values if were in the significant area can have a weak correlation. Negative values show an inverse relationship with the considered parameters (red under line and bold number).

According to the ion frequency to better understand the natural status of groundwater can be chemically determined using the modified Piper diagram and determination of the main anions and cations points on the graph, facies in the study area. In this section, Table 3 is considered together. From 2003 to 2015 , type of waters of sodium chloride to the water mixture and calcium-magnesium bicarbonate type of water that change the location. Generally, according to the depth of the alluvium in the middle, the chemical reactions times increases. In addition to increased dissolution of carbonate sediments from the highlands (weathering) to groundwater flow, bicarbonate and mixing of waters is formed. On the other hand because of water level drawdown intrusion of salt water from the drain to the middle part due to greatly reduced depth. One of the reasons for the decrease sodium-chloride water, disconnection between the discharge zones with the middle section. Another reason, by increasing the supply of incoming water (bicarbonate water) makes the waters of sodium chloride ( $\mathrm{Na}-\mathrm{Cl}$ penetration and spray of saline aquifers fossil) mix and create mixing water. In addition, the $\mathrm{pH}$ due to good dispersion in the range (in the range of neutral to slightly basic) had little effect on the reaction. In addition, as can be seen in Table 3, one of the most important factors is the increasing volume of

Table 3. Classification of groundwater resources in the study area of Ghaemshahr 3.

\begin{tabular}{|c|c|c|c|c|c|c|c|}
\hline Year & Wells (\%) & $\begin{array}{c}\text { Water } \\
\text { type (\%) }\end{array}$ & Range & Year & Wells & $\begin{array}{l}\text { Water } \\
\text { type }(\%)\end{array}$ & Range \\
\hline \multirow{10}{*}{2003} & W11, W16 (9.1) & \multirow{3}{*}{$\begin{array}{c}\mathrm{Ca}-\mathrm{Mg}-\mathrm{Cl} \\
(27.3 \%)\end{array}$} & Discharge & & W9, W20, W11 (13.6) & \multirow{3}{*}{$\begin{array}{l}\mathrm{Ca}-\mathrm{Mg}-\mathrm{Cl} \\
(31.8 \%)\end{array}$} & Discharge \\
\hline & W4, W5 (9.1) & & Middle & & W1, W12, W18, W13 (18.2) & & Middle \\
\hline & W22, W19 (9.1) & & Recharge & & ------ & & Recharge \\
\hline & W2, W9, W20 (13.6) & \multirow{3}{*}{$\begin{array}{c}\mathrm{Ca}-\mathrm{Mg}-\mathrm{HCO}_{3} \\
(45.4 \%)\end{array}$} & Discharge & & W2,W3, W10, W21 (18.2) & \multirow{3}{*}{$\begin{array}{c}\mathrm{Ca}-\mathrm{Mg}-\mathrm{HCO}_{3} \\
(63.6 \%)\end{array}$} & Discharge \\
\hline & $\mathrm{W} 12, \mathrm{~W} 13(9.1)$ & & Middle & \multirow{2}{*}{2015} & W4, W5, W15 (13.6) & & Middle \\
\hline & W7, W6, W8, W17, W14 (22.7) & & Recharge & & W7, W6, W8, W17, W14, W22, W19 (31.8) & & Recharge \\
\hline & W10, W21 (9.1) & \multirow{3}{*}{$\begin{array}{l}\mathrm{Na}-\mathrm{Cl} \\
(22.7 \%)\end{array}$} & Discharge & & W16 (4.5) & \multirow{3}{*}{$\begin{array}{l}\mathrm{Na}-\mathrm{Cl} \\
(4.5 \%)\end{array}$} & Discharge \\
\hline & W1, W15, W18 (13.6) & & Middle & & ---- & & Middle \\
\hline & ----- & & Recharge & & ---- & & Recharge \\
\hline & W3 (4.5) & $\mathrm{Na}-\mathrm{HCO}_{3}$ & Discharge & & & & \\
\hline
\end{tabular}


incoming water and the dissolution of carbonate rocks. For example, mixing water wells 22 and 19 which are of magnesium calcium bicarbonate waters in 2015, has become, which is caused by the above factors. Table 3, based on average annual are preparation and drawn. The disconnect between the middle and discharge, can at a minimum water table, water table drawdown caused due to uncontrolled and withdrawals. While the relationship at the maximum because of the increased volume of water entering the aquifer water table is re-established. In the direction of groundwater flow from the south to the north and northeast is the overflow drain region and thus goes out of range.

In Table 3, from 2003 to 2015 the percentage of water types has changed. Accordingly, the water calcium and magnesium bicarbonate from 45.4 to 63.6 percent compounded or mixed water (calcium-chloride-Magnesium) from 27.3 to 31.8 percent has increased. While, sodium chloride waters dropped from 22.7 to 4.5 percent has decreased. The reason for this change is related to the factors mentioned above.

As seen Table 3, this type of water is affected by the deposits of sand, clay, marl and silt from plain area, the deposits of limestone, marl and dolomite from highlands, as well as it originates the saline fluids' injection of saline fossil aquifer (connate water) and sea saltwater intrusion. The formation of this kind of facies as affected by the weathering and water-rock reaction; and therefore, large amounts of calcium, magnesium, and bicarbonate dissolved from highlands of the study area enter into the aquifer (recharge range). The waters are mixed due to groundwater flow direction and hydraulic gradient in its path, firstly with water-rock reaction from deposits of clay, marl, silt, and sand in the plain and secondly with saline fossil aquifers and salt water intrusion from Caspian sea (mid-range); and then with continuing the direction in the discharge area with direct penetration of seawater (North of the plain), create the type of water available in the study area.

Groundwater through flow path, available solution, carries large amounts of minerals due to the increase in reactions between rock and water and retention in the middle part from 2003 to 2015. Such a situation that the mineral can be dissolved in water and reached saturation point is defined as the saturation in$\operatorname{dex}(\mathrm{SI})$. When $\mathrm{SI}<1$, the minerals will be dissolved. If $\mathrm{SI}>1$, the mineral will be deposited. Given that there are not any deposit of gypsum and anhydride in the study area, so sulfate comes from two sources: 1) human activities including chemical fertilizers and urban, rural, and industrial sewage; and 2) sulfate inputs into the aquifer through the seawater. As a result, in the study area, saturation values of gypsum, anhydride and halite (in 2003 and 2015) in groundwater is negative, indicating the absence of these minerals is saturated. The reduction in 2015 would represent a reduction or optimal consumption of chemical fertilizers, urban, rural, and industrial wastewater management, and some of it is related to be absorbed through the roots of plants. Saturation values of calcite, aragonite and dolomite in 2003 and 2015 (except well 15 in 2015 which was almost saturated) all were positive and it means super-saturation. As observed, the 
intensity of saturation values of dolomite from south to north changes very little. But its changes from West to East had the declining volatility which is evident in the graph. These changes are much more intense in calcite and aragonite. Given that the flow direction is from south to north and northeast, groundwater's carry large amounts of calcium and magnesium bicarbonate solution; and reduction of the hydraulic gradient, speed reduction and the retention increase in the path cause the ion exchange between the alkali and earth alkaline. On the other hand, the significant amounts of groundwater from the West of the region were entered to the study area in the maximum water table and makes drastic changes in chemical reactions and as it moves towards the East, it will be less intensity which the problem can be caused by the mixing of groundwater. As a result, calcium bicarbonate, sodium bicarbonate, and sodium chloride are the dominant water type in the study area (in 2015). While in 2003, alongside the dominant type, waters have been existed with sodium sulfate (in the eastern part of recharge) and calcium sulfate (on the beach) types in the discharge limit. On the other side, given that all color-alkaline indexes were negative in 2003 and they were dropped to 50 percent in 2015 , it can be derived from a solution that is rich of alkali in some points and it would be rich from soil alkaline along the way. Therefore, ion exchange and reverse ion exchange in rock-water weathering reactions play an important role in terms of the exchange.

According to the above cases, factor analysis and principal component analysis methods were applied to classify the sampling points and the selected parameters of and then were studied and analyzed in basis of factor analysis from SPSS-16 software. Table 3 has been extracted for recognizing the contribution of factors' set in explaining the variance of each variable. The first column is the total variance amount of each variable which factors set can (are not able) explain it. Therefore, since the factors can explain all of the variances of a variable $(100 \%)$, in the table the amount of the variance is equal to 1 for all variables. The variance value of communalities was fluctuated between 0 and 1 and as much as it is closed to 1 , it will be better. Smaller values of variables are not suitable for factor analysis and they should be removed from the analysis. To communality of these variables, the factors should explain at least higher than $0.5 \%$ or $50 \%$. Communalities in both 2003 and 2015 were all above 0.5, indicating a high communality of variables' factors in the study area. Table 4 shows what percentage

Table 4. The eigenvalues of each factor with the cumulative variance percentage and after rotation it for 2003 and 2015 (using PCA method) (C: \% Cumulative, V: \% Variance, T: Total, F: Factor).

\begin{tabular}{|c|c|c|c|c|c|c|c|c|c|c|c|c|c|c|c|c|c|}
\hline \multirow{2}{*}{\multicolumn{3}{|c|}{$\begin{array}{c}\text { Primary } \\
\text { Feigenvalue (2003) }\end{array}$}} & \multirow{2}{*}{\multicolumn{3}{|c|}{$\begin{array}{l}\text { Loadings derived from the } \\
\text { sum of squares (2003) }\end{array}$}} & \multirow{2}{*}{\multicolumn{3}{|c|}{$\begin{array}{l}\text { eRotated loadings of the } \\
\text { sum of squares (2003) }\end{array}$}} & \multirow{2}{*}{\multicolumn{3}{|c|}{ Primary }} & \multicolumn{3}{|c|}{ Loadings derived from } & \multicolumn{3}{|c|}{ Rotated loadings of } \\
\hline & & & & & & & & & & & & & of squ & es $(2015$ & the su & of squ & es (2015) \\
\hline $\mathrm{T}$ & $\mathrm{V}(\%)$ & $\mathrm{C}(\%)$ & $\mathrm{T}$ & V (\%) & C (\%) & $\mathrm{T}$ & V (\%) & C (\%) & $\mathrm{T}$ & $\mathrm{V}(\%)$ & $\mathrm{C}(\%)$ & $\mathrm{T}$ & $\mathrm{V}(\%)$ & $\mathrm{C}(\%)$ & $\mathrm{T}$ & V (\%) & $\mathrm{C}(\%)$ \\
\hline 111.6 & 55.4 & 55.4 & 11.6 & 55.4 & 55.4 & 6.5 & 32.35 & 32.35 & 13.2 & 51.02 & 51.02 & 13.2 & 51.02 & 51.02 & 13.2 & 51.02 & 51.02 \\
\hline 24.18 & 20.4 & 75.8 & 4.18 & 20.40 & 75.80 & 6.3 & 31.36 & 63.71 & 3.1 & 19.43 & 70.45 & 3.1 & 19.43 & 70.45 & 3.1 & 19.43 & 70.45 \\
\hline 32.29 & 11.4 & 87.2 & 2.29 & 11.4 & 87.20 & 3.5 & 16.16 & 79.87 & 1.9 & 16.53 & 88.98 & 1.9 & 16.53 & 88.98 & 1.9 & 16.53 & 88.98 \\
\hline 41.8 & 8.52 & 95.72 & 1.8 & 8.52 & 95.72 & 3.3 & 15.85 & 95.72 & 1.1 & 10.23 & 97.21 & 1.1 & 10.23 & 97.21 & 1.1 & 10.23 & 97.21 \\
\hline
\end{tabular}


each factor can explain of the variance of the set of variables. This table is prepared for both years and is explained as the total variance. In this table, the primary eigenvalues are determinant of the factors that remain in the analysis (the factors which have eigenvalues less than 1 are excluded from the analysis). Results for both the years show that four factors have eigenvalues more than 1, and they remain in the analysis and could explain as a whole, $94.09 \%$, and $95.46 \%$ of the total variance of the 21 variables for 2003 and 2015, respectively. The results from Table 4 (based on Table 3) shows: based on the eigenvalues (total column), only the factors are selected which have values more than $1(>1)$. The contribution of each factor is specified in explaining the variance extracted of 21 variables in the column of the variance percentage and the first factor had the most contribution that in 2003 was $55.06 \%$ with eigenvalue of 11.56 and the least was $8.18 \%$ with eigenvalue of 1.7 and in 2015 , the variance percentage was $69.68 \%$ with eigenvalue of 14.63 and the least was $5.2 \%$ with eigenvalue of 1.09 . As seen in the Table 4, there are four factors more than one that it can be stated that 21 variables are actually reducible to four factors.

The aim of factor analysis is the explanation and justification of the observed correlation. This means that factors need to be certain and then be interpreted accordingly. To achieve this goal, not rotating solutions do not work. The reason for this is that the identification of the factors that have a large number of factor loading is difficult and on the other hand, there is not an ideal and complete solution in the analysis. There are two graphical methods for rotating in the software SPSS, each of which contains several subsidiary methods. The correlation test (Pearson correlation coefficient) is used to detect the rotational method. The results of correlation analysis showed that all four factors have no correlation with each other (the significant level is more than 0.05 and the relationship between factors is not significant.); so varimax rotation is used on rotation factor in following. Table 5 shows the rotation matrix of factors, including factor loadings of each of the remaining variables after the varimax rotation. The variables that have high loading on each factor are shown (the loadings less than 0.5 have been removed).

Factor loading of the variables that were less than 0.5 has been deleted from Table 5. As well as each variable in the factor that has more factor loading is considered. The four identified factors called R-mode has been extracted in both years. In 2003 and 2015, saturated with gypsum and anhydride were in factor-1 with negative factor loading which means these variables have a negative correlation with the total factor and other variables. Given that there are no deposits of gypsum in the region, the problem results from the pollution of human activity and the use of chemical fertilizers in the range. The increase in 2015 reflects the increased reactivity and reduced sulfate, resulting from sulfate absorbed through the roots of plants, optimum use of sulfate fertilizers, and its reduction.

The following can be briefly derived from the study of Table 5 for 2003 and 2015: 
Table 5. Rotated matrix of factors (R-mode) after deriving factors to identify the variables and their factor loading (2003 and 2015) (extraction method: PCA; and rotation method: varimax, Kaiser normalization: the red numbers show an inverse relationship).

\begin{tabular}{|c|c|c|c|c|c|c|c|c|c|}
\hline $\begin{array}{c}\text { Variables } \\
(2003)\end{array}$ & $\begin{array}{c}\text { Factor-1 } \\
(2003)\end{array}$ & $\begin{array}{c}\text { Factor-2 } \\
(2003)\end{array}$ & $\begin{array}{c}\text { Factor-3 } \\
(2003)\end{array}$ & $\begin{array}{c}\text { Factor-4 } \\
(2003)\end{array}$ & $\begin{array}{c}\text { Variables } \\
(2015)\end{array}$ & $\begin{array}{c}\text { Factor-1 } \\
(2015)\end{array}$ & $\begin{array}{c}\text { Factor-2 } \\
\text { (2015) }\end{array}$ & $\begin{array}{c}\text { Factor-3 } \\
\text { (2015) }\end{array}$ & $\begin{array}{c}\text { Factor-4 } \\
(2015)\end{array}$ \\
\hline EC & 0.59 & 0.82 & 0.16 & 0.16 & EC & 0.88 & 0.37 & 0.21 & 0.15 \\
\hline TDS & 0.57 & 0.81 & 0.14 & 0.15 & TDS & 0.881 & 0.37 & 0.2 & 0.16 \\
\hline $\mathrm{PH}$ & -0.22 & 0.05 & 0.93 & -0.19 & PH & 0.06 & -0.09 & 0.98 & -0.003 \\
\hline $\mathrm{Ca}$ & 0.83 & 0.19 & 0.38 & 0.25 & $\mathrm{Ca}$ & 0.77 & 0.54 & 0.23 & 0.15 \\
\hline $\mathrm{Mg}$ & 0.91 & 0.15 & 0.14 & 0.21 & $\mathrm{Mg}$ & 0.79 & 0.5 & 0.28 & 0.1 \\
\hline $\mathrm{Na}$ & 0.2 & 0.97 & 0.075 & 0.067 & $\mathrm{Na}$ & 0.91 & 0.27 & 0.18 & 0.18 \\
\hline $\mathbf{K}$ & 0.74 & 0.44 & 0.006 & 0.23 & $\mathbf{K}$ & 0.49 & 0.56 & 0.36 & 0.38 \\
\hline $\mathrm{HCO}_{3}$ & 0.35 & 0.18 & 0.28 & 0.83 & $\mathrm{HCO}_{3}$ & 0.44 & 0.84 & 0.23 & -0.14 \\
\hline $\mathrm{Cl}$ & 0.24 & 0.95 & 0.11 & -0.1 & $\mathrm{Cl}$ & 0.91 & 0.21 & 0.18 & 0.25 \\
\hline $\mathrm{SO}_{4}$ & 0.77 & 0.52 & -- & -0.26 & $\mathrm{SO}_{4}$ & 0.93 & 0.22 & 0.14 & 0.07 \\
\hline TDI & 0.58 & 0.79 & 0.17 & 0.15 & TDI & 0.92 & 0.29 & 0.18 & 0.12 \\
\hline SI (calcite) & 0.27 & 0.06 & 0.878 & 0.36 & SI (calcite) & 0.3 & 0.45 & 0.83 & -0.01 \\
\hline SI (aragonite) & 0.29 & 0.06 & 0.879 & 0.36 & SI (aragonite) & 0.3 & 0.45 & 0.83 & -0.01 \\
\hline SI (dolomite) & 0.54 & 0.19 & 0.72 & 0.36 & SI (dolomite) & 0.47 & 0.57 & 0.66 & 0.06 \\
\hline SI (anhydrate) & -0.72 & -0.5 & 0.02 & 0.32 & SI (anhydrate) & -0.93 & -0.22 & -0.14 & -0.07 \\
\hline SI (gypsum) & -0.72 & -0.5 & 0.02 & 0.32 & SI (gypsum) & -0.93 & -0.22 & -0.14 & -0.07 \\
\hline SI (halide) & 0.26 & 0.93 & 0.02 & -0.07 & SI (halide) & 0.96 & 0.01 & 0.1 & 0.1 \\
\hline Alkalinity. & 0.37 & 0.18 & 0.33 & 0.83 & Alkalinity. & 0.37 & 0.88 & 0.16 & -0.03 \\
\hline CAI & 0.16 & 0.06 & -0.02 & -0.8 & CAI & 0.16 & 0.15 & -0.15 & 0.910 \\
\hline CAII & 0.17 & -0.81 & 0.07 & -0.44 & CAII & 0.22 & -0.22 & 0.13 & 0.913 \\
\hline TH & 0.89 & 0.16 & 0.31 & 0.22 & TH & 0.79 & 0.52 & 0.25 & 0.12 \\
\hline$\%$ Variance & 32.35 & 31.36 & 16.16 & 15.85 & $\%$ Variance & 51.02 & 19.43 & 16.53 & 10.23 \\
\hline Total & 32.35 & 63.71 & 79.87 & 95.72 & Total & 51.02 & 70.45 & 88.98 & 97.21 \\
\hline
\end{tabular}

- The percentage of total variance is the most impressive in factor-1 is that 31.24 percent and 50.08 percent for 2003 and 2015, respectively; in other words, positive and strong factor loading has been created by increasing the percentage of variance in 2015. In 2003, the highest and lowest elements were potassium and magnesium cations, respectively; and it represents cation exchange, the presence of hardness that can be the result of water-rock weathering along the groundwater flow path; and the presence of sulfate, given that there is no gypsum deposits, can be caused by human infection and leakage of chemical fertilizers, especially sulfated fertilizers, through conducting the surface activities to aquifer and due to their leaching. While in 2015, the highest elements were sulfate, sodium, chloride and TDI and the least element was calcium. This is primarily the result of the intrusion of salt water (the existence of brackish fossil aquifers under fresh aquifer and sea water intrusion) that actually chlorine serves as an indicator. Pumping too much can also lead to accelerate the salt water intrusion and the deterioration of groundwater (Cheng et al., 2005). High levels of TDS are also indicative of 
the abundance of present elements in groundwater. In addition, the evaporation process continues with silicate clay minerals' weathering (Na-plagioclases) and pollution from human activities. Due to geological condition and the relatively good relation of anions and cations, hardness, EC, and TDS, impact of calcareous sediments, dolomite, and marl can play an important role in chemical changes and the interactions between groundwater solution and sediments.

- In factor-2, the percentage of the total variance achieved 30.28 and 19.15 percent, respectively, which represents high influencing of the variables in 2003 with positive and relatively strong factor loading compared to 2015. In this factor (2003), the most effective factor was intrusion of salt water (brackish fossil aquifers and sea), followed by saturated halite. In this factor, chloro-alkaline-II has opposite relation with variables which it can be observed that its increase results in ion exchange decrease. As in this factor, ion exchange has not taken place.

- In factor-3, total variance percentage was obtained 16.79 percent and 16.57 percent, respectively, indicating equal effectiveness with a good to relatively weak positive loading to each other. As seen in Table 5, the greatest impact was on $\mathrm{pH}$ and in following were calcite, aragonite, and dolomite. Given that the $\mathrm{pH}$ value was $7.5-8.2$ in 2003 , and it was $6.9-7.9$ in 2015 , and it just has well to strong correlation with saturated calcite, aragonite and dolomite; it can be stated that it was scattered in both years as weak to neutralize alkali in the entire area. As a result, the sedimentary media and dissolution and ion exchange are especially created for calcareous, dolomite and marl sediments of recharge limitation and cause them to be saturated. A change can be seen in 2015 as in 2003, as it can be seen in the percentage of variance.

- In factor-4, total variance percentage was 15.78 and 9.64 percent, respectively, that it reflects higher effectiveness of variable in 2003 with positive and weak factor loading compared to 2015. Bicarbonate, alkalinity, and color-alkaline have the highest impact in factor-4. In 2015, only color-alkaline I and II have been effective; that is the ion exchange and its reverse has been the most important parameters. In general, according to being neutralized $\mathrm{pH}$ in both years, the most influential factors were in chemical reactions of alluvial aquifer of Ghaemshar plain in 2003; the minerals dissolution out of the aquifer from limestone, dolomite and marl (carbonate + clay) formations (entrance of calcium and magnesium bicarbonate with clay from south of Alborz mountain heights) and their entrance into the aquifer as well as from sediments of clay, silt and volcanic ash (sodium and potassium solution), organic matter decomposition cause to occur reverse ion exchange; and sodium and potassium are replaced with calcium and magnesium resulting in negative chloro-alkaline-I (reverse ion exchange). Additionally, salt water intrusion (sodium chloride) from brackish fossil aquifers and sea causes taken reactions in the aquifer. For this reason, mixed water $(\mathrm{Ca}-\mathrm{Mg}-\mathrm{Cl})$ and sodium chloride water are formed from recharge to discharge of calcium and 
sodium bicarbonate, respectively. But in 2015, chemical reactions cause ion exchange and its reverse in the study area and it plays an important role. The type of composed waters is almost identical to 2003; the only difference is that the number of wells that have been salted is increased.

Based on the factor scores (in variables, R-mode, and wells, Q-mode), it can be considered three modes in the formation of chemical reactions which these reactions occur between groundwater, geological formations, and intrusion of salt water (brackish fossil aquifer and seawater intrusion). To detect these interactions between variables and the wells are within range, combined graph is drawn that shows link between the wells and the variables. The sum of these two loadings which has the greatest impact in 2003, 61.54 percent, is increased to 69.23 percent in 2015. In total, the increase was not significant, but the changes of each of loadings individually are significant, for example; F1 was about 30 percent in 2003, while it was increased in 2015 to 50 percent. On the other hand, the loading F2 from 30 percent in 2003 shows a decrease to 19 percent in 2015. The factor loadings vary between \pm 1 that in this area, well 5 in 2003 and only wells 18, 16 and 7 in 2015 are out of the range, but total variables are in range. In 2003 , only 5 wells located on the beach in the plains output. The well came under the influence of salt water has high salinity. In 2015, all three wells in the central area of the West to the East and the Western Aquifer wells 7 under the influence of low quality and the two other wells of brackish fossil aquifers feeding, and its quality is reduced. For this reason, these wells are located outside of \pm 1 .

Given that the factor loadings can be interpreted as correlation coefficients, with observing Table 2 and drawn factor loadings can be seen high harmony. For example, the parameters of EC, TDS, TDI, Na, and $\mathrm{Cl}$ have the correlation between 0.75 and 1, respectively. Factor loadings of these parameters in both years were more than 0.8 , which is shows a high correlation coefficient and factor loadings. In fact, the two in supporting each other, help remarkably to interpret the factor analysis and principal component analysis. In 2015, the percentage of variance of factor- 1 had a significant increase in compared to factor- 2 and factor-3, and the salinity has the most effectiveness in factor-1 which represents the intrusion of salt water (brackish fossil aquifer through spray, leakage and sea saltwater intrusion into fresh aquifer) and the factor of harmful human activities had a lesser role than in 2003, which could be due to the control and efficient use of fertilizers. In factor- 2 and factor-3, bicarbonate and alkalinity (dissolution of minerals, cation exchange, and decomposition of organic matter) have had the most impact along with the dissolution and saturation.

Ion exchange and its reverse ion exchange had the main impact in Factor-4. The considerable interest is creating direct relationship of $\mathrm{pH}$ with other parameters. Overall, the percentage of the total variance and factors show significant shifts from 2003 to 2015 that these changes are caused by three main factors, including weathering and dissolution of minerals (calcareous, dolomite, and marl sediments), evaporation and crystallization (excessive harvesting, water table drawdown and subsequent minerals' deposition and their re-dissolution and 
their returning to groundwater) and salt water intrusion. Meantime, given that there is not the evaporate deposits (gypsum and halide), a high level of sulfate anion is related to pollution from human activities.

\section{Discussion}

The applied methods significantly and worth fully contribute the development and facilitation of determining of hydro-geochemical characterizations in the study area. These applied methods are a combination of factor analysis, principal component analysis and combined charts with hydro-geochemical conventional methods. In the taken analyses, the following points have been considered:

According to the studies, hydro-geochemical changes are considerably evident from south to north and north-east (from recharge to discharge) in the direction of groundwater flow and also from West to East. Accordingly, this study showed that three important factors play a major role in controlling hydro-geochemical reactions in the plain area. These factors include weathering and interaction between water and rock, evaporation and crystallization, and saltwater intrusion through brackish fossil aquifer in the middle of the plain and sea saltwater intrusion in coastal and discharge section. As a result, sodium (dissolution of silicates and leakage of saline solutions), chloride (penetration of atmospheric precipitation, leakage of saline solutions, and evaporation from discharge range) ions and weathering calcareous, dolomite, and marl sediments, which causes the release of calcium, magnesium and bicarbonate ions and thus the ions dissolved in the groundwater are used as key parameters in tracking the effects of the dissolution of carbonate, silica and salt solutions and sulfate minerals as original ions in chemical reactions. Thus, according to Piper chart, there are five types of water in 2003, from recharge to discharge, respectively, as a result of weathering and dissolution with pollutions that arises from human activities. In the end, salt water intrusion is effective on the chemical composition. From 2003 to 2015 the percentage of water types has changed. Three types of water formed in 2015, it seems that the pollutions were declined due to optimum use of fertilizers and some absorption of it through plants' roots; and the type of sulfate water has not been created. Since the plain has been made like a drum shape, it can be stated that most of chemical reactions occur due to high durability in the middle range. This represents an increase of chemical reactions in the range of weathering and interaction between water and rock; and its transferring to the middle part and its mixing with salt water leakage caused calcium and magnesium of deposits take place ion exchange with sodium and potassium, association with saline solution through the path and also reverse ion exchange occurs in the same area. Overall in the study area from 2003 to 2015 due to the rapid advance along the path of groundwater flow of salt water injections of saline fossil groundwater and intense human activities (urban waste water, agricultural and industrial) have been effective in altering the chemical composition of groundwater.

The disconnect between the middle and discharge, can at a minimum water table, water table drawdown caused due to uncontrolled and withdrawals. While 
the relationship at the maximum because of the increased volume of water entering the aquifer water table is re-established. In the direction of groundwater flow from the south to the north and northeast is the overflow drain region and thus goes out of range.

\section{Conclusion}

Factor analysis and principal component analysis were performed for 21 variables and 22 wells, suggesting that four factors have allocated 94 and 95 percent of the total variance in 2003 and 2015, respectively. Of these four factors, factors 1 and 2 have had the greatest impact on the area, 61.52, and 66.65 percent, respectively. While in 2003, pollution from human activities and weathering were placed in factor-1, and salinity was placed in factor-2; it is recognized that this is salinity to become factor- 1 in 2015 , which reflects saltwater intrusion and further advancement through the sea and the leakage and spray salt solutions from brackish fossil aquifer. This is due to the indiscriminate withdraws and continues to use the wrong methods of irrigation. Therefore, the large drop of water table and the pressure reduction in the fresh aquifer in the middle part, as well as low quality waters' overflow down into the studied aquifer from the western part of the region in spring are effective in lowering the quality of groundwater resources of Ghaemshahr-Joybar plain. The factor loadings map on the quality (R-mode) and the place of wells (Q-mode) represents further progress intrusion of saltwater in the area. On the other hand, combined diagrams and correlation between factor grades 1 and 2 with variables reflect the right selection on using factor analysis and principal component analysis to help and complement the usual method in hydro-geochemistry.

\section{References}

[1] APHA (2005) Standard Methods for the Examination of Water and Wastewater. $19^{\text {th }}$ Edition, American Public Health Association, Washington D.C., USA, 1467.

[2] Chadha, D.K. (1998) A New Diagram for Geochemical Classification of Natural Waters and Interpretation of Chemical Data. Bhu-Jal, 13, 1-4.

[3] Cheng, P.J., Huang, Y.C. and Wu, T.N. (2005) Characterization of Groundwater Quality by Multivariate Statistical Analysis: An Example from Kaohsiung County, Taiwan. In: Mathew, K. and Nhapi, I., Eds., Water and Wastewater Management for Developing Countries, Water and Environment Management Series, IWA Publishing, London.

[4] Franks, F. (2000) Water a Matrix of Life. 2nd Edition, RSC Paperbacks, UK, 225.

[5] Gharemahmudlu, M., Raghimi, M. and Tahmasebi, A. (2007) Using Hydro-Geochemistry Studies for the Detection of Salt Water Intrusion into Water Wells (Case Study of Sari City). Journal of Agricultural Sciences and Natural Resources, 15.

[6] Kalantari, N., Rahimi, M.H. and Cherchi, A. (2007) The Application of Combined Diagrams, Factor Analysis and Saturation Profiles in Qualitative Assessment of Groundwater of Zoweircherry and Kherran Plains. Journal of Engineering Geology, 1 .

[7] Mazandaran Regional Water Authority (2016) Statistics of Measuring the Water Level of Observational Wells, Chemical Analysis and Other Information and Re- 
ports.

[8] Momeni, M. (2007) The Statistical Analysis by Using SPSS. New Book Press, Tehran.

[9] Sedaghat, M. (1975) Review Problem of Progress and Seawater Intrusion in the Coastal Plain of the Caspian Sea. Graduate Thesis, University of Tehran, Iran.

[10] Singh, S.K., Singh, C.K., Kumar, K.S., Gupta, R. and Mukherjee, S. (2009) SpatialTemporal Monitoring of Groundwater Using Multivariate Statistical Techniques in Bareilly District of Uttar Pradesh, India. Journal of Hydrology and Hydromechanics, 57, 45-54.

[11] Zarechahooki, M.A. (2010) Multivariate Analysis Methods in SPSS Software. Tehran University Press, Tehran.

Submit or recommend next manuscript to SCIRP and we will provide best service for you:

Accepting pre-submission inquiries through Email, Facebook, LinkedIn, Twitter, etc. A wide selection of journals (inclusive of 9 subjects, more than 200 journals)

Providing 24-hour high-quality service

User-friendly online submission system

Fair and swift peer-review system

Efficient typesetting and proofreading procedure

Display of the result of downloads and visits, as well as the number of cited articles

Maximum dissemination of your research work

Submit your manuscript at: http://papersubmission.scirp.org/

Or contact ojg@scirp.org 